\title{
Airborne Gram Negative Bacilli in the Indoor Environment of King Abdullah University Hospital, Jordan and Their Antibiotic Susceptibility
}

\author{
Ismail Saadoun*1 and Ibraheem Ali Al Tayyar ${ }^{2}$ \\ ${ }^{1}$ Department of Applied Biology, University of Sharjah, United Arab Emirates \\ ${ }^{2}$ Department of Applied Biological Sciences, Jordan University of Science and Technology, Jordan
}

Received: May 11, 2018; Published: May 21, 2018

*Corresponding author: Department of Applied Biology, University of Sharjah, P.O. Box 27272, Sharjah, United Arab Emirates,

\begin{abstract}
This study aimed to evaluate the presence of airborne Gram negative bacilli (GNB) in the operating theatres (OT), intensive care units (ICU) and nursery intensive care units (NICU) of King Abdullah University Hospital (KAUH), Jordan and their susceptibility to different antibiotics. Thirty four air samples of 100 liters volume/min were collected by a microbiological air sampler from the above units during seven months. Air samples were impacted on trypticase soy agar (TSA) then incubated at $37^{\circ} \mathrm{C}$ for $48 \mathrm{~h}$. Each bacterial colony appeared on agar plates were sub-cultured on TSA or blood agar with incubation at $37^{\circ} \mathrm{C}$ for $24-48 \mathrm{~h}$, and then identified by standard methods. The average bacterial count in the OT, ICU and NICU was 88,118 and $125 \mathrm{cfu} / \mathrm{m}^{3}$, respectively. From all GNB, Pseudomonas aeruginosa comprised $45 \%, 33.9 \%$ and $31 \%$ in the NICU, ICU and OT air samples, respectively. However, each of Acinetobacter spp. and Aeromonas spp. comprised 19.6\% in the ICU and NICU air samples. Citrobacter freundii in the ICU comprised 28.3\%. GNB bacilli showed a considerable resistance to antibiotics with the highest to nalidixic acid (38.2\%) and to cloxacillin (32.4\%), and the lowest to augmentin (3.6\%) and to chloramphenicol (3.1\%). It is concluded that designing of monitoring strategies should continue to keep monitoring of the presence and distribution of GNB in the hospitals' environment. The extensive use of some antibiotics in hospitals for longer periods may lead to higher percentage resistance of GNB.
\end{abstract}

Keywords: Airborne; Antibiotic; Bacteria; Gram negative bacilli; Hospital

Abbreviations: GNB: Gram Negative Bacilli; OT: Operating Theaters; ICU: Intensive Care Unit; Nursery Intensive Care Unit; KAUH: King Abdullah University Hospital; HAI: Hospital Acquired Infections; MRSA: Methicillin Resistant Staphylococcus aureus; TSA: Trypticase Soy Agar; MIO: Motility Indole Ornithin; MR-VP: Methyl Red-Voges Proskauer; TSI: Triple Sugar Iron; NCCL: National Committee for Clinical Laboratory

\section{Introduction}

Indoor air quality of hospitals is remarkably important because the hospital environment is full of pathogens which may cause nosocomial and other infections through airborne exposure. Airborne bacteria are one of these pathogens and evaluation of their count, types and diversity in hospitals rooms especially operating theatres (OT), intensive care units (ICU) and nursery intensive care units (NICU) is very important to control and prevent hospital acquired infections (HAI) as approximately $10 \%$ of all patient infections are suspected to be hospital-acquired [1].

In a previous study for the airborne methicillin-resistant Staphylococcus aureus (MRSA) in the indoor environment of a referral university hospital, King Abdullah University Hospital (KAUH), Jordan, Saadoun et al. [2] had identified 9.3\% MRSA from all samples collected from the different wards of the hospital. In this study we report the measurements of airborne Gram negative bacilli (GNB) present in different wards of KAUH. Isolation and identification of airborne GNB genera and/or species being impacted from the indoor environments of these units, and detection of the sensitivity of the isolates to commonly used antibiotics were also reported.

\section{Materials and Methods}

\section{The Studied Hospital}

The KAUH used for monitoring purpose is a modern general hospital that was established in 2002 with a total capacity of 850 beds and a total staff of over 2000, and is located in Jordan University of Science and Technology in Irbid city in Northern 
Jordan. Airborne GNB bacteria were studied in OT, ICU and NICU of the hospital; each ICU and NICU consisted of three separated different size rooms and OT consists of eight operating rooms. The temperature in these three rooms is maintained at $22^{\circ} \mathrm{C} \pm 2^{\circ} \mathrm{C}$ all year around.

\section{Collection of Air Samples}

A total of 34 air samples were collected from three sensitive units of KAUH. Fourteen separated samples were collected from the OT, and 10 other samples were collected from each of the ICU and the NICU. Each air sample was collected by a microbiological air sampler (M.A.Q.S.II-90)/ OXOID, UK) that holds $90 \mathrm{~mm}$ Petri dishes within an autoclavable anodized aluminum head of 380 holes. The sampler was set at an air-sampling rate $100 \mathrm{~L} / \mathrm{min}$ for two minutes per sample. Duplicated air samples were collected from each visit at different sites of each unit with a $1 \mathrm{~m}$ elevation from the floor (i.e. the same level of the patient's bed). Samples from the OT were collected early morning before the operations when the room was empty while samples in ICU and NICU were taken at different times in the day.

\section{Sample Processing}

After impacting the air samples on trypticase soy agar (TSA) media plates, they were transported to the laboratory and immediately incubated at $37^{\circ} \mathrm{C}$ for $48 \mathrm{~h}$ to determine the total GNB count. Diversity and total counts of bacteria on TSA plates were recorded by using the colony counter (560, Suntex, Labolan). Each grown GNB bacterial colony was sub-cultured on a suitable or a special medium to isolate the bacteria in a pure form for further identification and confirmation.

\section{Bacterial Isolation and identification}

Each bacterial colony appeared on agar plates was sub-cultured on TSA or blood agar (Oxoid, UK) and incubated aerobically at 35 ${ }^{\circ} \mathrm{C}$ for 24-48 h. Bacterial identification was based on macroscopic and microscopic examination (Gram staining) and furthermore with specific biochemical tests. Based on Gram stain results, each bacterial colony was sub-cultured under aseptic conditions on different culture media for isolation, identification and testing the susceptibility of the isolates for common used antibiotics.

Table 1: Number of isolated bacteria/ $\mathrm{m}^{3}$ and percentage distribution of Gram negative bacteria in operating theatres (OT), intensive care units (ICU) and nursery intensive care units (NICU) of King Abdullah University Hospital in Irbid, Jordan.

\begin{tabular}{|c|c|c|c|}
\hline $\begin{array}{c}\text { Bacteria } \\
\text { (Number, Diversity and Type) }\end{array}$ & $\begin{array}{c}\text { Operating Theatres } \\
\text { (OT) }\end{array}$ & $\begin{array}{l}\text { Intensive Care Units } \\
\text { (ICU) }\end{array}$ & $\begin{array}{l}\text { Nursery Intensive Care Units } \\
\text { (NICU) }\end{array}$ \\
\hline \multicolumn{4}{|l|}{ Number of bacteria } \\
\hline Range & $0-200$ & $30-250$ & $40-220$ \\
\hline Average & 88 & 118 & 125 \\
\hline \multicolumn{4}{|l|}{ Diversity of bacteria } \\
\hline Range & $0-11$ & 8-Feb & $11-\mathrm{Feb}$ \\
\hline Average & 4 & 5 & 6 \\
\hline \multicolumn{4}{|l|}{$\begin{array}{l}\text { Percentage distribution of isolated } \\
\text { Gram negative bacteria }\end{array}$} \\
\hline Pseudomonas aeruginosa & 31 & 33.9 & 45 \\
\hline Acinetobacter & ND* & 19.6 & 19.6 \\
\hline Aeromonas & ND & 19.6 & 19.6 \\
\hline Cirobacter freundii & ND & 28.3 & ND \\
\hline
\end{tabular}

${ }^{*}$ ND: Not Determined

\section{Identification of Gram Negative Bacilli (GNB) Bacteria}

Identification of GNB was performed based on the morphological characterization of each isolate as per the standard method [3] and including color, size, and colony characteristics (form, margin, and elevation). The Gram stain test was performed on each isolate. Members of the family Enterobacteriaceae and other nonfastidious, non-enteric Gram negative bacilli such as Pseudomonas, Acinetobacter, Aeromonas were further identified using the API $20 \mathrm{E}$ system (Biomerix, France). The test was performed according to the manufacturer instruction by which the strips were incubated aerobically at $37{ }^{\circ} \mathrm{C}$ for $24 \mathrm{hr}$ and the results were interpreted by change in the color and the use of analytical profile index (Biomerix, France, Ref. 20 190). All results were collected on the provider data sheet, compared and confirmed with the results obtained from the conventional identification tests and methods such as Gram stain and biochemical tests including: oxidase production, motility, indole, ornithin decarboxylase (MIO), methyl red-Voges Proskauer (MR-VP), carbohydrate utilization test: triple sugar iron (TSI) tests.

\section{Antimicrobial Susceptibility Test}

Test organism from isolated culture was activated by inoculation into Mueller-Hinton broth or trypticase soy broth (Oxoid, UK) and incubated at $37^{\circ} \mathrm{C}$ for $24 \mathrm{~h}$. Turbidity of organisms in the broth was adjusted to be equal to or greater than $0.5 \mathrm{McF}$ arland turbidity standards (1.5 x $108 \mathrm{cfu} / \mathrm{ml})$. Mueller-Hinton agar plates and 0.5 McFarland standards were prepared according to the recommendation of Kirby-Bauer disc diffusion procedure [4] and National 
Committee for Clinical Laboratory (NCCLS) [5].The test organisms were homogeneously inoculated by a sterile cotton swab on the surface of two freshly prepared Mueller-Hinton agar plates. Plates were incubated at $37^{\circ} \mathrm{C}$ for $24 \mathrm{~h}$. Twenty two different antibiotics discs (Oxoid, UK) (Table 2) were used for susceptibility test of GNB. Antibiotic disks were applied gently to the agar surface by a sterile forceps, and then plates were inverted and incubated at $35^{\circ} \mathrm{C}$ for 16-18 h. The results of susceptibility test (inhibition zone diameter) for each isolate were measured in $(\mathrm{mm})$ and interpreted according to NCCL standards [5] on a special data sheet.

\section{Statistical Analysis}

Data were processed by the SPSS statistical software (SPSS for windows, Version 10.0.1, SPSS Inc, USA). Comparisons between groups (units) were tested by one way ANOVA test and Comparison between two independent samples were done through the use of the T-test. Two tailed $\mathrm{P}$ values $<0.05$ was considered significant.

\section{Results}

In this study the average bacterial count was 88, 118 and 125 $\mathrm{cfu} / \mathrm{m} 3$ in OT, ICU and NICU, respectively; and ranged between 0 and 200, 30 and 250, and 40 and $220 \mathrm{cfu} / \mathrm{m}^{3}$, in OT, ICU and NICU, respectively, while the bacterial diversity ranged between 0 and 11 , 2 and 8, 2 and 11, respectively (Table 1). Total air bacterial count and diversity in all units were not significantly different (P-value $=0.258$ ). Nevertheless, bacterial counts in OT were less than ICU, NICU (Table 2) with an average count of $88 \mathrm{cfu} / \mathrm{m}^{3}$. Bacterial diversity was similar in all hospital units. The results of cultured samples identified three major groups of bacteria: Gram positive cocci (93\%), Gram positive bacilli (2\%) and GNB (5\%). From all GNB, Pseudomonas aeruginosa comprised 31\%, 33.9\% and $45 \%$ in the OT, ICU and NICU air samples, respectively (Table 1). P. aeruginosa was the major GNB isolated from the air of all units of the hospital. However, each of Acinetobacter spp. and Aeromonas spp. comprised $19.6 \%$ in the ICU and NICU air samples. Citrobacter freundii in the ICU comprised $28.3 \%$ (Table 1). Other genera as Enterobacter, and Proteus were also identified.

Table 2: Antibiotic panel used for Gram negative bacilli and their percentage of resistance.

\begin{tabular}{|c|c|c|c|}
\hline Antibiotic & Symbol & $\begin{array}{c}\text { Concentration } \\
(\boldsymbol{\mu g})\end{array}$ & \% of Resistance \\
\hline Amikacin & AK & 3 & $8 \%$ \\
\hline Amoxicillin & AX & 25 & $15.40 \%$ \\
\hline Ampicillin & AM & 10 & $14.40 \%$ \\
\hline Augmentin & AUG & 30 & $3.60 \%$ \\
\hline Azithromycin & AZM & 15 & - \\
\hline Bacitracin & B & 10 & - \\
\hline Cefaclor & CEC & 30 & $24.30 \%$ \\
\hline Ceftriaxone & CRO & 30 & $18.20 \%$ \\
\hline Cefotaxime & CTX & 30 & $23 \%$ \\
\hline Cefoxitin & FOX & 30 & - \\
\hline Cefuroxime & CXM & 30 & $26.80 \%$ \\
\hline Chloramphenicol & C & 30 & $3.10 \%$ \\
\hline
\end{tabular}

\begin{tabular}{|c|c|c|c|}
\hline Ciprofloxacin & CIP & 5 & $6.10 \%$ \\
\hline Clarithromcin & CLR & 15 & - \\
\hline Cloxacillin & CX & 30 & $32.40 \%$ \\
\hline Erytromycin & E & 15 & $18.60 \%$ \\
\hline Gentamicin & CN & 10 & $5.70 \%$ \\
\hline Imipenem & IPM & 10 & $12 \%$ \\
\hline Linezolid & LZD & 30 & $26.80 \%$ \\
\hline Nalidixic acid & NA & 20 & $38.20 \%$ \\
\hline Novobiocin & NV & 30 & - \\
\hline Ofloxacin & OFX & 10 & - \\
\hline Oxacillin & OX & 1 & - \\
\hline Penicillin & P & 10 & $15.40 \%$ \\
\hline Rifampin & RA & 10 & $25.60 \%$ \\
\hline Rifampicin & RP & 5 & $12.30 \%$ \\
\hline Streptomycin & S & 300 & $20.70 \%$ \\
\hline Tetracycline & TE & 30 & $5.60 \%$ \\
\hline Trimethoprim & SXT & 30 & $4.60 \%$ \\
\hline
\end{tabular}

The different antibiotics that are commonly used in Jordan were evaluated against all GNB bacterial isolates (Table 2) by the disc diffusion method. Results indicated that the higher percentage resistance of GNB was resistant to nalidixic acid (NA) 38.2\%, cloxacillin (CX) 32.4\%, cefuroxime (CXM) 26.8\%, linezolid (LZD) 26.6\%, refampin (RA) 25.6\%, cefaclor (CEC) $24.3 \%$, cefotaxime (CTX) $23 \%$, and streptomycin (S) $20.7 \%$. However, the isolates showed a remarkable lower resistant (3.1\% to $18.6 \%)$ to erythromycin (E) 18.6\%, ceftriaxone (CRO) 18.2\%, amoxicillin (AX) and penicillin (P) $15.4 \%$ each, $14.4 \%$ to ampicillin (AM) $14.4 \%$, rifampicin (RP) $12.3 \%$, imipenem (IPM) $12 \%$, amikacin (AK) $8 \%$, ciprofloxacin (CIP) 6.1\%, gentamycin (CN) 5.7\%, tetracycline (TE) 5.6\%, trimethoprim (SXT) 4.6\%, 3.6\% to augmentin (AUG) 3.6\%, and chloramphenicol (C) 3.1\% (Table 2).

\section{Discussion}

Results indicated that OT has less bacterial counts and diversity than the other wards. This is due to the high sanitary standards in OT, as compared to other hospital areas which are affected by many factors that increase the total bacterial count in the air. These factors include the number of visitors, cases of patients, opened doors and the amount of material brought from outside, such as flowers, gifts and foods [6,7]. These are recognized as sources of hospital contamination [8]. Increased bacterial diversity is usually related to the total bacterial count. In this study, the bacterial diversity was similar in all hospital units. Part of the diversity was related by Ross and Menezes [9] to the high temperature and relative air humidity that favors microbial growth. Similar to our results, Beggs [10] reported that approximately two thirds of microorganisms isolated from the hospitals air were Gram positive cocci; this group represents a higher proportion of microorganisms in operating rooms.

In a similar study to evaluate the airborne GNB in the indoor environment of six different hospitals in Northern Jordan serving a population of 1.3 million, Saadoun and Al Tayyar [11] found that 
GNB comprised $2.35 \%, 1.57 \%$ and $1.58 \%$ of the average bacterial count in OT, ICU and NICU, respectively. The very low presence of Gram negative Enterobacteriaceae is an indicative of the hospital cleanness as these Enterobacteriaceae normally are associated with human gut and their presence signifies the poor hygienic practices and thus their presence work as indicators for contamination [12]. In addition, the results can be related to the different factors such as human activities, number of visitors and the number of procedures conducted in the ward $[10,13]$.

P. aeruginosa was the major GNB isolated from the air of all units of the hospital. This can be explained by its association with different types of human infections or because this bacterium is resistant to many of the disinfectants and antiseptics commonly used in hospitals. The considerable higher percentage resistance (> 20\%) of GNB to nalidixic acid, cloxacillin, cefuroxime, linezolid, refampin, cefaclor, cefotaxime, and streptomycin may explain the extensive use of these antibiotics in the hospital for long time. On the other side, the isolates showed a remarkable lower resistance (<20\%) to erythromycin, ceftriaxone, amoxicillin and penicillin, ampicillin, rifampicin, imipenem, amikacin, ciprofloxacin, gentamycin, tetracycline, trimethoprim, augmentin, and chloramphenicol. These results indicate that these antibiotics are still acceptable alternatives for GNB bacterial infection treatments in the hospital and the area in general, and the four antibiotics (tetracycline, trimethoprim, augmentin, and chloramphenicol) that have the lowest resistance may play an important role to prevent nosocomial infection in KAUH.

\section{Conclusion}

High sanitary standards is important to achieve less bacterial counts in different wards of the hospitals and designing of monitoring strategies should continue to keep monitoring of the presence and distribution of GNB in the hospitals' environment. The extensive use of some antibiotics in hospitals for longer periods may leads to higher percentage resistance of GNB. Nevertheless, other antibiotics are still acceptable alternatives for GNB bacterial infection treatments in hospitals and may play an important role to prevent nosocomial infections.

\section{Acknowledgment}

Deanship of Scientific Research at Jordan University of Science and Technology funded this research (Grant No. 37/2005). Special thanks are extended to University of Sharjah for administrative support.

\section{References}

1. Meers PD, Ayliffe GAV, Emmerson AM (2002) Report of the national survey in hospitals infections. Merck Manual 2: 1-583.

2. Saadoun I, Jaradat Z, Al Tayyar I, El Nasser Z, Ababneh Q (2014) Airborne methicillin resistant Staphylococcus aureus (MRSA) in the indoor environment of King Abdullah University Hospital. Jordan Indoor Built Environment.

3. Balows A, Hausler WJ, Herrmann KL, Isenberg HD, Shadomy HJ (1991) Manual of Clinical Microbiology ( $5^{\text {th }}$ edn.), Washington DC, USA.

4. Bauer AW, Kirby WM, Sherris JC, Turk M (1966) Antibiotic susceptibility testing by a standardized single disc method. Am J Clinic Pathol 45: 493496.

5. (2003) National Committee for Clinical Laboratory Standards 2003, Methods for dilution antimicrobial susceptibility test for bacteria that grow aerobically: Approved standards M7-A6 and N2-A8, NCCLS.

6. Saad SG (2003) Integrated Environmental Management for Hospitals. Indoor Built Environment 12: 93-98.

7. Sessa R, Di PM, Schiavoni G, Santino I, Altieri A, et al. (2002) Microbiological indoor air quality in healthy buildings. New Microbiol 25(1): 51-56.

8. Kalliokoski P (2003) Risks caused by airborne microbes in hospitalssource control is important. Indoor Built Environment 12: 41-46.

9. Ross C, Menezes JR, Terezinha Inez Estivalet SvidzinskiII, Ulisses AlbinoI, Galdino Andradel (2004) Studies on fungal and bacterial population of air-conditioned environments. Braz Arch Biol Technol 47(5): 827-835.

10. Beggs CB (2003) The airborne transmission of infection in hospital buildings: fact or fiction? Indoor Built Environment 12: 9-18.

11. Saadoun I, Al Tayyar I (2013) Evaluation of susceptibility of airborne Gram negative bacilli bacteria in operating theaters and intensive care units in North Jordan Hospitals, Jordan. Sebha Medical Journal 12(2): 40-47.

12. Hewitt KM, Mannino FL, Gonzalez A, Chse JH, Caporaso JG, Knight R, et al. (2013) Bacterial diversity in two neonatal intensive care units (NICUs). PLoS One 8: e54703.

13. Obbard JP, Fang LS (2003) Airborne concentrations of bacteria in a hospital environment in Singapore. Water Air and Soil Pollution 144: 333-341.
This work is licensed under Creative Commons Attribution 4.0 License

Submission Link: https://biomedres.us/submit-manuscript.php

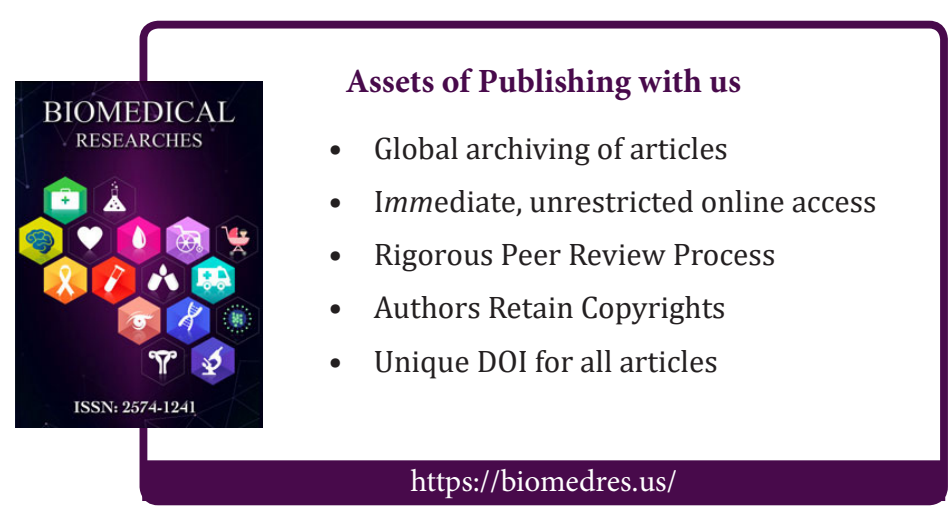

